\title{
ATRIAL SEPTAL DEFECT WITH PULMONARY HYPERTENSION
}

\author{
BY \\ EDWIN BESTERMAN \\ From the Department of Cardiology, the Middlesex Hospital
}

Received February 27, 1961

Pulmonary hypertension occurs less frequently in atrial septal defect (A.S.D.) than in shunts at ventricular or aorto-pulmonary levels. Nevertheless it is a serious complication of A.S.D. that leads to severe disability, predisposes to pulmonary thrombosis, and constitutes the main contraindication to surgical closure of the defect. It is rare below the age of 20 and relatively common after the age of 40 years.

This paper deals with 41 cases of A.S.D. complicated by significant pulmonary hypertension. A systolic pulmonary arterial pressure above $50 \mathrm{~mm}$. Hg at catheterization confirmed the diagnosis in 35 patients, and the diagnosis was based on central cyanosis and post-mortem findings in 6. Thirty-six patients were investigated at the Middlesex Hospital during 1956-1958 while 5 relate to an earlier series (Bedford et al., 1941) in which case records and post-mortem findings were available.

Incidence. Pulmonary hypertension, as defined, occurred in 16 per cent of 225 cases of A.S.D. seen at the Middlesex Hospital, but in only 6 per cent was the pulmonary pressure high enough to reverse the atrial shunt. Wood (1958) estimated the incidence of severe pulmonary hypertension (Eisenmenger reaction) to be at least six times as great in large aorto-pulmonary or ventricular shunts as in large A.S.D., and this agrees with the experience of Swan (1954) and of Scebat et al. (1957). Bedford and Sellors (1960) reported pulmonary hypertension, as defined, in 18 per cent of 300 consecutive cases of A.S.D. and its incidence was 4 per cent below the age of 20,18 per cent between 20 and 40, and 40 per cent over the age of 40 years.

\section{Hamodynamic PATtern}

It is important to distinguish between hyperkinetic pulmonary hypertension due mainly to increased flow, and obstructive hypertension due mainly to an increased vascular resistance. When the vascular resistance exceeded 5 units (400 dynes/sec. $/ \mathrm{cm}^{-5}$ ) hypertension has been arbitrarily classed as obstructive, and when the resistance was below this level, and the left-to-right shunt considerable, hypertension has been classed as hyperkinetic. Surgical closure of an A.S.D. complicated by obstructive hypertension with a small, balanced, or reversed shunt is unlikely to be beneficial and may well prove harmful because the safety valve action of a reversed shunt is lost. Swan (1959) reported the results of operation in three patients with obstructive pulmonary hypertension: two died immediately and the survivor showed no regression of pulmonary hypertension after operation. McGoon et al. (1959) reported 5 operative deaths in 7 cases of A.S.D. with high pulmonary vascular resistance, and Liddle et al. (1960) 6 operative deaths in 15 cases of A.S.D. with pulmonary hypertension exceeding $50 \mathrm{~mm}$. $\mathrm{Hg}$.

In the present series of 41 patients, pulmonary hypertension was obstructive in 30 , hyperkinetic in 7, and associated with Lutembacher's syndrome in 4 patients who have been grouped separately as they presented distinctive features. 


\section{ANATOMICAL TyPE OF A.S.D.}

Ostium primum defects were diagnosed in 3 instances, two with obstructive and one with hyperkinetic pulmonary hypertension; the latter proved to have a common A-V canal at operation. Wood (1958) found pulmonary hypertension in 43 per cent of 21 cases of common atrio-ventricular canal or ostium primum, and Keith et al. (1958) have emphasized its frequency in primum defects in children. In the Middlesex Hospital series of A.S.D. the diagnosis of an ostium primum type has been made altogether in 56 cases, and in 32 of them the clinical diagnosis has been confirmed at operation or at necropsy or both. In these 56 pulmonary hypertension (exceeding $50 \mathrm{~mm}$. systolic) occurred in only $7(12 \cdot 5 \%)$. The Middlesex series related almost entirely to adults and children aged over 5 years, so that children with the more serious malformations such as complete common A-V canal with a ventricular shunt who die early were obviously excluded. Nevertheless, the idea that pulmonary hypertension is the rule in the ostium primum defect does not apply to patients who survive to adolescence or adult life and may then have a clinical course that is relatively benign.

Bedford (1960) in 15 cases of primum defect, proved at operation or necropsy, found the pulmonary arterial pressure normal in $4,30-50 \mathrm{~mm}$. systolic in 8 , and $80 \mathrm{~mm}$. systolic in one patient with a common A-V canal. Of the two not catheterized, one presented signs of pulmonary hypertension with a reversed shunt, and the other no evidence of it. He suggests that pulmonary hypertension occurs below the age of 20 only in primum defects with a common A-V canal and a significant ventricular shunt.

Superior caval (sinus venosus) defects were present in 4 of this series, three having obstructive and one hyperkinetic hypertension. The incidence of pulmonary hypertension was more than twice as great in S.V.C. defects as in fossa ovalis defects in the Middlesex Hospital cases.

\section{SEX AND AgE}

The ratio of women to men was 4 to 1 in the present series of 41 patients, whereas it was 2 to 1 in the 225 patients with A.S.D. uncomplicated by pulmonary hypertension. The age of those with pulmonary hypertension ranged from 2 to 63 years, the average age at the time of reporting or at death being 36 years. Thirty-one patients survived the age of 30 (Table I).

TABLE I

Age Incidence of Pulmonary Hypertension in A.S.D.

\begin{tabular}{cc|c|c|c|c|c|c|c|c}
\hline Age & & $0-10$ & $11-20$ & $21-30$ & $31-40$ & $41-50$ & $51-60$ & $\begin{array}{c}\text { Over } \\
60\end{array}$ & Total \\
\hline Obstructive group &. & 3 & 1 & 4 & 7 & 11 & 3 & 1 & 30 \\
\hline Hyperkinetic group &. & 1 & 0 & 1 & 2 & 3 & 0 & 0 & 7 \\
\hline Lutembacher group &.. & 0 & 0 & 0 & 1 & 3 & 0 & 0 & 4 \\
\hline Total .. &. & 4 & 1 & 5 & 10 & 17 & 3 & 1 & 41 \\
\hline
\end{tabular}

\section{Symptoms and Clinical Signs}

Cardiac symptoms developed before the age of 20 in one-third of the obstructive and in twothirds of the hyperkinetic group, the average age at the onset of symptoms being 28 and 15 years respectively (Table II). Palpitation and dyspnœa were the earliest and most frequent symptoms (Table III). Palpitation could be related to paroxysmal arrhythmias in 6 cases, but usually it was due to an over-active right ventricle. Dyspnœa, often severe, was the presenting complaint in 38 patients. Orthopnœa occurred in 43 per cent of the obstructive and in 86 per cent of the hyperkinetic group, and was often related to respiratory infection. 
TABLE II

Age of OnSET OF Symptoms in 40 CASES

\begin{tabular}{cc|c|c|c|c|c|c|c}
\hline Age & & $0-10$ & $11-20$ & $21-30$ & $31-40$ & $41-50$ & $51-60$ & Average \\
\hline Obstructive group .. &. & 6 & 3 & 6 & 7 & 6 & 1 & 28 \\
Hyperkinetic group .. & $\ldots$ & 4 & 1 & - & 2 & - & - & 15 \\
Lutembacher group &.. & - & - & - & 4 & - & - & 34 \\
\hline
\end{tabular}

TABLE III

Symptoms in A.S.D. With Pulmonary Hypertension

\begin{tabular}{|c|c|c|c|c|c|c|c|}
\hline & & & & & $\begin{array}{l}\text { Obstructive } \\
\text { (30 cases) }\end{array}$ & $\begin{array}{l}\text { Hyperkinetic } \\
\text { (7 cases) }\end{array}$ & $\begin{array}{l}\text { Lutembacher } \\
\text { (4 cases) }\end{array}$ \\
\hline None & . & . & . & . & $4 \%$ & - & - \\
\hline Dyspnœa (Grade 1-2) & . & . & . & . & $23 \%$ & - & - \\
\hline Dyspnœa (Grade 3-4) & . & . & . & . & $73 \%$ & $100 \%$ & $100 \%$ \\
\hline Orthopnœa & . & . & . & . & $43 \%$ & $86 \%$ & $100 \%$ \\
\hline Congestive failure.. & $\cdots$ & $\cdots$ & $\cdots$ & $\cdots$ & $33 \%$ & $86 \%$ & $100 \%$ \\
\hline Palpitation & . & . & . & . & $70 \%$ & $100 \%$ & $100 \%$ \\
\hline Recurrent bronchitis & . & . & . & . & $50 \%$ & $86 \%$ & $100 \%$ \\
\hline Hæmoptysis & . & . & . & . & $20 \%$ & $14 \%$ & - \\
\hline Fatigue $\quad .$. & . & $\cdots$ & . & $\cdots$ & $23 \%$ & $43 \%$ & - \\
\hline Ischæmic pain & . & $\cdots$ & . & . & $23 \%$ & - & - \\
\hline Syncope .. & . & . & . & . & $17 \%$ & - & - \\
\hline
\end{tabular}

Congestive heart failure occurred in 49 per cent of the patients, more frequently in the hyperkinetic group, and recurrent respiratory infection was common. Hæmoptysis occurred in 7 patients, being related to respiratory infection in 5 and to pulmonary thrombosis in 2. Fatigue was a major symptom in one-quarter of the total. Anginal pain on effort occurred in 7, and in 3 of them there was also effort syncope. Syncope, like pain, occurred only in the obstructive group, but in contrast to pain it was invariably associated with severe disability. The duration of symptoms in the 41 patients averaged 12 years, being longest in the hyperkinetic group. Once symptoms appeared, deterioration was more rapid in the obstructive than in the hyperkinetic group.

The principal signs are given in Table IV. Cyanosis of peripheral type was common in all the patients, but central cyanosis was limited to the obstructive group. The average age at onset of central cyanosis was 32 years; in 4 instances its onset was sudden and due to thrombosis of a major pulmonary artery. About half of the centrally cyanosed patients also had finger clubbing.

Atrial fibrillation occurred in 10 patients, including all the Lutembacher group, 3 out of 7 hyperkinetic ones, but only 3 out of 30 with obstructive hypertension. The jugular venous pressure was raised in 40 per cent of the whole group, but a dominant "a" wave was seen in only 5 patients, all with obstructive hypertension.

Auscultation. Obstructive pulmonary hypertension modified the usual auscultatory signs of A.S.D. in a characteristic way. The pulmonary systolic murmur was rarely loud and in 8 it was 
TABLE IV

Physical Signs in A.S.D. with Pulmonary Hypertension

\begin{tabular}{|c|c|c|c|c|c|c|c|}
\hline & & & & & $\begin{array}{l}\text { Obstructive } \\
\text { (30 cases) }\end{array}$ & $\begin{array}{l}\text { Hyperkinetic } \\
\text { (7 cases) }\end{array}$ & $\begin{array}{l}\text { Lutembacher } \\
\text { (4 cases) }\end{array}$ \\
\hline Cyanosis (central) .. & . & . & . & . & $63 \%$ & 0 & 0 \\
\hline $\begin{array}{lll}\text { Clubbing } & . . & . .\end{array}$ & . & . & . & . & $30 \%$ & 0 & 0 \\
\hline Atrial fibrillation .. & .. & . & $\ldots$ & . & $10 \%$ & $43 \%$ & $100 \%$ \\
\hline J.V.P._-"a" dominant & .. & .. & .. & .. & $17 \%$ & 0 & 0 \\
\hline Right ventricular lift & .. & . & . & . & $97 \%$ & $100 \%$ & $100 \%$ \\
\hline Ejection sound & . & . & .. & . & $70 \%$ & $43 \%$ & $50 \%$ \\
\hline Systolic murmur absent & .. & .. & .. & .. & $27 \%$ & 0 & 0 \\
\hline S.M. (Grade 1-2) .. & .. & $\cdots$ & . & .. & $67 \%$ & $43 \%$ & $25 \%$ \\
\hline S.M. (Grade 3-4) .. & . &.. & .. &. & $3 \%$ & $57 \%$ & $75 \%$ \\
\hline Second sound split (Grad & le $1-2)$ & . & .. & . & $80 \%$ & $71 \%$ & $50 \%$ \\
\hline Second sound split (Grac & le $3-4)$ & .. & .. & .. & $13 \%$ & $29 \%$ & $50 \%$ \\
\hline$P_{2}$ loud & .. & .. & .. & .. & $100 \%$ & $100 \%$ & $100 \%$ \\
\hline Pulmonary D.M. ... & .. & .. &.. & .. & $43 \%$ & 0 & $50 \%$ \\
\hline $\begin{array}{ll}\text { Tricuspid D.M. } & \text {.. } \\
\end{array}$ & $\cdots$ & $\cdots$ & $\cdots$ & $\cdots$ & $17 \%$ & $100 \%$ & $100 \%$ \\
\hline Tricuspid S.M. & . & . & . & . & $20 \%$ & $29 \%$ & 0 \\
\hline Mitral S.M. & $\cdots$ & $\cdots$ & $\cdots$ & $\cdots$ & $3 \%$ & 0 & 0 \\
\hline Mitral D.M. & . & . & . & . & $3 \%$ & 0 & $75 \%$ \\
\hline Atrial sound & . & . & .. & . & $13 \%$ & 0 & 0 \\
\hline
\end{tabular}

absent, while a systolic ejection sound was present in 70 per cent. Splitting of the second sound was close, the pulmonary element was always loud, and in almost half there was a diastolic murmur of pulmonary regurgitation. The tricuspid diastolic flow murmur was rarely heard $(17 \%)$.

Hyperkinetic hypertension modified the usual signs of A.S.D. to a much less degree. The pulmonary systolic murmur was always present and often loud, splitting of the second sound was usually obvious, and a pulmonary diastolic murmur was never heard, whereas the tricuspid diastolic murmur was always present. An over-active right ventricle and loud pulmonary valve closure often provided the only clinical evidence of hyperkinetic pulmonary hypertension.

Phonocardiograms were recorded in 20 patients and confirmed the clinical evaluation of the split second sound. The widest splitting clinically measured $0.06 \mathrm{sec}$. on the phonocardiogram, and this only occurred in 4 patients, none of whom had obstructive hypertension. Besides the murmurs mentioned, a mitral systolic murmur was heard in one case with a primum defect, a tricuspid systolic in those with gross heart failure, and a mitral diastolic in those with Lutembacher's syndrome.

\section{Cardiac Catheterization}

Thirty-five patients were catheterized and the relevant data are summarized in Table V. The pulmonary systolic pressure was raised to systemic level or higher in only 5 of 25 with obstructive 
TABLE V

Catheter Findings in 35 Patients

\begin{tabular}{|c|c|c|c|c|c|c|c|c|}
\hline & & & & & & Obstructive & Hyperkinetic & Lutembacher \\
\hline \multicolumn{4}{|c|}{ Pulmonary/systemic flow ratio (average) } & . & \multirow{2}{*}{$\begin{array}{l}\cdots \\
\ldots\end{array}$} & $1 \cdot 35 / 1$ & $4 / 1$ & $3 \cdot 5 / 1$ \\
\hline ” & ” & , & (range) & . & & $0 \cdot 5 / 1$ to $3 \cdot 2 / 1$ & $2 \cdot 5 / 1$ to $7 \cdot 5 / 1$ & $3 / 1$ to $4 / 1$ \\
\hline \multicolumn{5}{|c|}{ Pulmonary vascular resistance } & \multirow{3}{*}{$\begin{array}{l}\cdots \\
\cdots \\
\cdots\end{array}$} & 1024 & 248 & 240 \\
\hline Units (average) & . & .. & .. & .. & & $12 \cdot 8$ & $3 \cdot 1$ & $3 \cdot 0$ \\
\hline Units (range) & . & .. & .. & .. & & $5-38$ & $2 \cdot 5-4 \cdot 4$ & $2 \cdot 5-4 \cdot 0$ \\
\hline \multicolumn{2}{|c|}{$\begin{array}{l}\text { Pulmonary blood flow } \\
\text { (1./min.) (average) }\end{array}$} & . & . & $\cdots$ & .. & $4 \cdot 6$ & $13 \cdot 4$ & $12 \cdot 0$ \\
\hline \multicolumn{2}{|c|}{ (1./min.) (range) .. } & .. & . & .. & .. & $1 \cdot 5-8 \cdot 6$ & $9 \cdot 0-20 \cdot 4$ & $10 \cdot 4-13 \cdot 2$ \\
\hline \multicolumn{6}{|c|}{ Pulmonary/systemic systolic pressure (average) ... } & $91 / 111$ & $65 / 117$ & $77 / 125$ \\
\hline \multicolumn{6}{|c|}{ Arterial $\mathrm{O}_{2}$ saturation (average) } & $85 \%$ & $93 \%$ & $95 \%$ \\
\hline
\end{tabular}

hypertension. The average pulmonary pressures were lower in the hyperkinetic than in the obstructive group, but a wide range was found. Significant arterial oxygen desaturation, due to a bidirectional or reversed shunt, was found only in the obstructive cases.

In patients with a high resistance, the severity of the dyspnœea increased pari passu with a diminution or reversal of the left-to-right shunt, as shown in Table VI. Syncope occurred only in patients with a small, balanced, or reversed shunt, but anginal pain was not obviously related to the hæmodynamic findings. The average systemic blood flow of $3.71 . / \mathrm{min}$. in the cases with pain was lower than the level of 5.31 . $/ \mathrm{min}$. found in the patients with syncope, but the significance of this difference is doubtful in such a small series.

TABLE VI

Symptoms Related to Catheter Data in Obstructive Pulmonary Hypertension

\begin{tabular}{|c|c|c|c|c|}
\hline & & $\begin{array}{l}\text { Pulmonary/ } \\
\text { systemic } \\
\text { blood flows }\end{array}$ & $\underset{\text { percentage }}{\text { Arterial } \mathrm{O}_{2}}$ & No. of cases \\
\hline Dyspnœea (Grade 1-2) & .. & $1 \cdot 7 / 1$ & $88 \%$ & 5 \\
\hline Dyspnœa (Grade 3) & .. & $1 \cdot 3 / 1$ & $84 \%$ & 11 \\
\hline Dyspnœa (Grade 4) & .. & $1 \cdot 1 / 1$ & $82 \%$ & 7 \\
\hline Syncope ... & $\begin{array}{ll}\ldots & \ldots\end{array}$ & $0.9 / 1$ & $87 \%$ & 5 \\
\hline Ischæmic pain $\quad$. & .. $\quad \ldots$ & $1 \cdot 5 / 1$ & $89 \%$ & 6 \\
\hline
\end{tabular}

Of the physical signs in obstructive hypertension, tricuspid diastolic murmurs occurred only in 4 patients with an average flow ratio of 2 to 1 . The murmur was present in all the hyperkinetic and Lutembacher cases, in which an increased pulmonary flow was invariably present. Pulmonary diastolic murmurs were found only in those with severe hypertension and an average resistance of 18 units.

\section{RADIOLOGY}

The heart size varied greatly but on average it was smaller in the obstructive than in the other groups (Table VII). The radiological pattern of the pulmonary vasculature in A.S.D. cannot 
TABLE VII

Cardio-Thoracic Ratios in A.S.D. With Pulmonary Hypertension

\begin{tabular}{lll|c|c|c}
\hline & & & Obstructive & Hyperkinetic & Lutembacher \\
\hline Average & $\ldots$ & $\cdots$ & $61 \%$ & $73 \%$ & $76 \%$ \\
\hline Range & $\cdots$ & $\cdots$ & $42-82 \%$ & $53-85 \%$ & $66-84 \%$ \\
\hline
\end{tabular}

always be relied on to distinguish between obstructive and hyperkinetic hypertension, though extreme degrees can readily be differentiated. In this respect fluoroscopy may be more informative. Excessive pulsation of the right ventricle and pulmonary vessels suggests a large pulmonary flow and a low vascular resistance, whereas a quiet heart with little arterial pulsation suggests a relatively small flow and a high resistance.

\section{Pulmonary Arterial Thrombosis}

This was diagnosed in 10 patients, all with obstructive hypertension. Four had calcification of a main pulmonary artery and another four presented angiocardiographic evidence of thrombosis, the diagnosis being confirmed at necropsy in two of them (Fig. 1 and 2). In the remain-

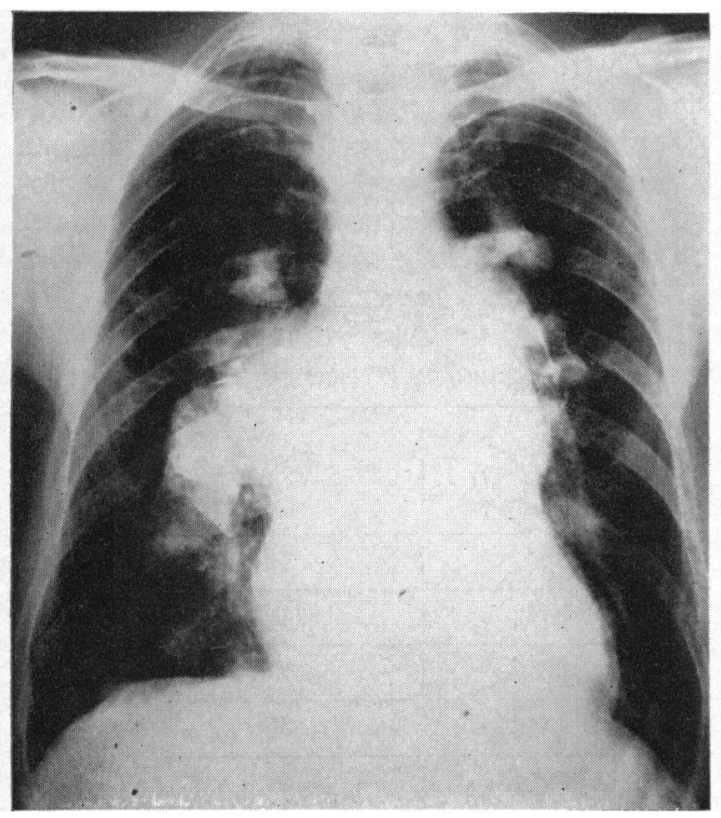

Fig. 1.-Bilateral calcification of pulmonary arteries due to thrombosis. ing two patients, pulmonary thrombosis occurred as a terminal complication after operation. Thrombosis developed during an acute respiratory infection in 5 patients, in 2 of whom it proved fatal, but one has survived it for 12 years.

Thrombosis of a main pulmonary artery was described as a complication of A.S.D. by Bedford et al. (1941). More recently it has been emphasized as important in cases with pulmonary hypertension by Dexter (1956) and by Campbell et al. (1957) who found it in four such cases at necropsy.

\section{ELECTROCARDIOGRAM}

Of 31 cases in sinus rhythm, a $\mathrm{P}$ pulmonale ( $3 \mathrm{~mm}$. or more in amplitude) was present in 10, including 9 obstructive and 1 hyperkinetic.

Right axis deviation and a vertical position were present in all cases except the 3 with ostium primum defects. The ÂQRS in cases without complete right bundle-branch block showed a difference between the obstructive and hyperkinetic groups. In a majority of the obstructive group the electrical axis fell within sextant 4 of the triaxial system $\left(+120^{\circ}\right.$ to $\left.+180^{\circ}\right)$, whereas in most of the hyperkinetic group it fell in sextant $5\left(+60^{\circ}\right.$ to $\left.+120^{\circ}\right)$ like the cases with normal pressures (Table VIII). Complete right bundle-branch block was present in 13: in the remainder, the different patterns seen in lead V1 appear to indicate no more than positional differences in the presence of right ventricular hypertrophy (Fig. 3). The frequency of these patterns is shown in Table IX and it can be seen that there is no correlation between any one pattern and the right ventricular systolic pressure. Likewise, the duration of the intrinsicoid deflection in lead V1 showed no 
IG. 2.-Necropsy specimen from same case as Fig. 1, showing massive thrombosis with calcification in right pulmonary artery. Right atrium opened to show A.S.D.

TABLE VIII

Electrical Axis in Fossa-ovalis Defects Without Complete Right B.B.B.

Obstructive pulmonary hypertension
Hyperkinetic pulmonary hypertension
ASD without pulmonary hypertension
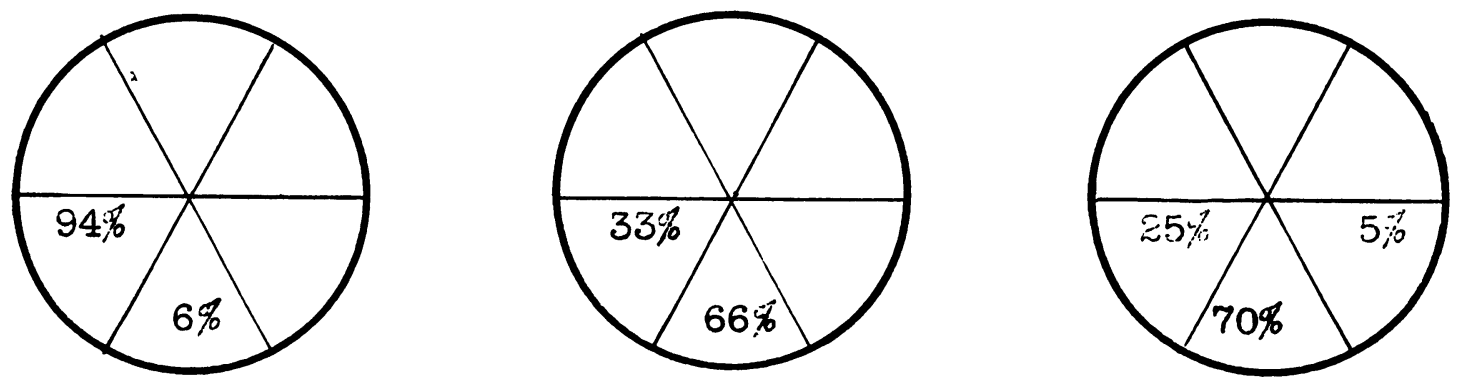

correlation with the degree of hypertension. There was no significant difference between the R/S ratios in leads V1 and V6 in the obstructive and hyperkinetic groups, but the R/S ratio in V1 appeared to be of some value in distinguishing between A.S.D. with normal, and A.S.D. with raised pressures. Inversion of the T waves extending from lead V1 to V 5 or V6 was present in 75 per cent of 
all cases without complete right bundle-branch block, and in 80 per cent of those with it. This pattern is therefore of value in the diagnosis of pulmonary hypertension but does not help to separate the obstructive from the hyperkinetic variety.

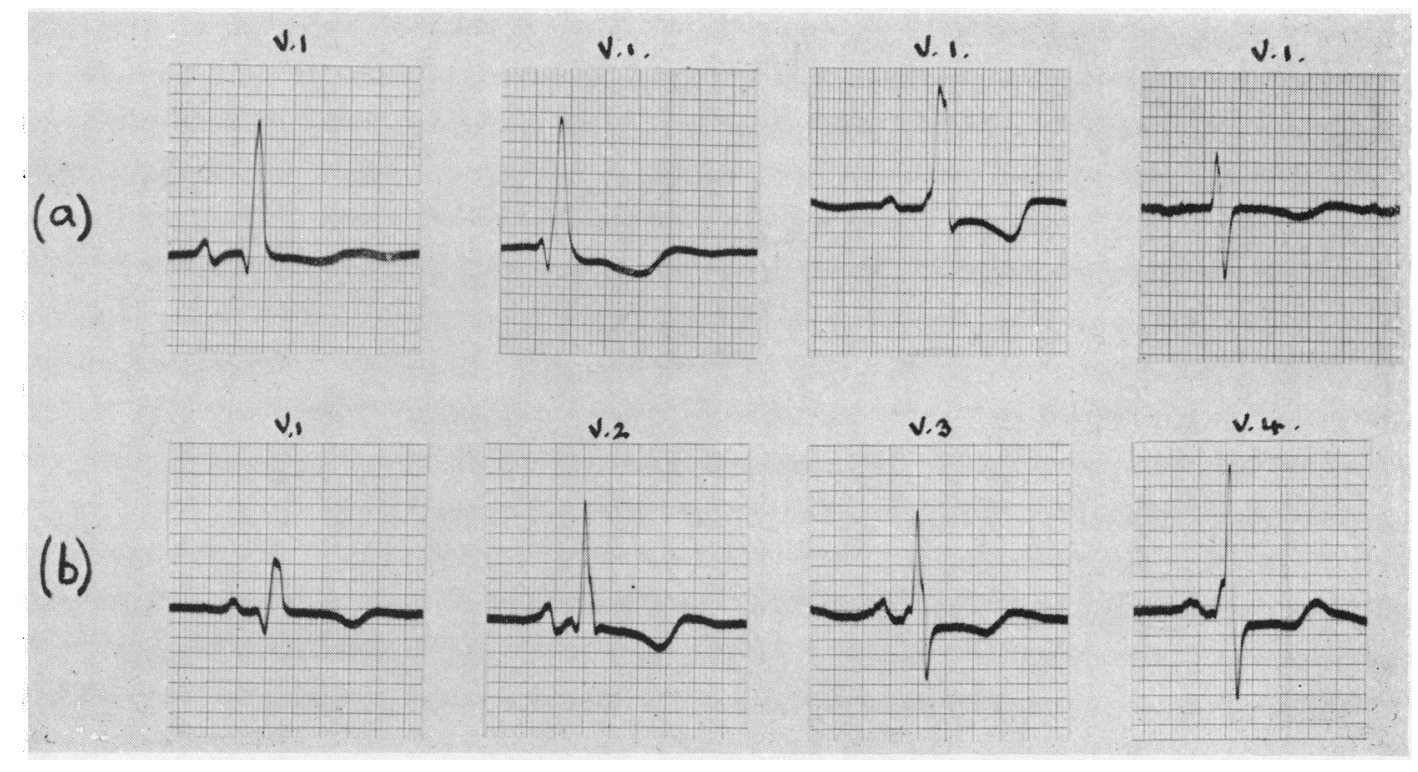

FIG. 3.-(a) Four different patterns of QRS observed in lead V1. (b) Leads V1-V4 from one patient with obstructive hypertension, showing $\mathrm{T}$ inversion.

TABLE IX

Ventricular CoMpleXes in V1

\begin{tabular}{|c|c|c|c|c|c|c|c|c|c|c|}
\hline Pattern in V1 & .. & .. & $\Gamma$ & 1 & $N$ & $\sqrt{1}$ & $\Lambda$ & $\Lambda$ & R.B.B.B. & $\begin{array}{l}\mathbf{R} / \mathbf{S} \\
\mathrm{mm} .\end{array}$ \\
\hline Obstructive group ... & .. & 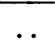 & 2 & 4 & 2 & 3 & 1 & 6 & 10 & $14 / 1$ \\
\hline Hyperkinetic group .. &.. & $\ldots$ & - & 3 & 1 & - & - & 2 & 1 & $12 / 1$ \\
\hline Lutembacher group &.. & $\overline{.}$ & - & 2 & - & - & - & - & 2 & $11 / 1$ \\
\hline Average R.V.P. mm. Hg & .. & 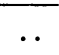 & 90 & 78 & 78 & 83 & 90 & 92 & - & - \\
\hline
\end{tabular}

LUTEMBACHER'S SYNDROME

The pulmonary arterial pressure is usually above the normal limits in Lutembacher's syndrome and it exceeded $50 \mathrm{~mm}$. systolic in almost half of all cases corrected surgically at the Middlesex Hospital (Table XI). The usual hæmodynamic pattern is a much increased pulmonary flow, a slightly raised pulmonary vascular resistance, and hyperkinetic pulmonary hypertension. Of the four cases in this series, three were classed as hyperkinetic and one, not catheterized, was placed in the obstructive group on grounds of terminal central cyanosis and of histological changes found in 
the small pulmonary vessels at necropsy. Nevertheless, when seen two years before death, this patient was acyanotic and presented a gross hilar dance at radioscopy, indicating an excessive pulmonary flow and large shunt, so that the hypertension had almost certainly been hyperkinetic in the earlier stages. In the presence of a large A.S.D., mitral stenosis must tend to restrict the systemic and to increase the pulmonary flow, and in the three patients catheterized the pulmonary to systemic flow ratio averaged 3.5 to 1 , the vascular resistance averaging 3 units.

The Lutembacher cases have been considered separately because they presented certain special clinical features. They were all aged over 30, their hearts were larger than those in the other groups, and all had atrial fibrillation and congestive failure. Cardiac symptoms developed later than in others, but once they appeared deterioration was rapid so that the patients were all severely disabled within 5 years.

In regard to clinical diagnosis, auscultatory signs of mitral stenosis were minimal and it was difficult to distinguish between the mitral diastolic murmur and the usual tricuspid diastolic murmur of atrial septal defect with a large pulmonary flow. When a patient aged over 30 with A.S.D. has an unusually large heart, an excessive pulmonary flow, pulmonary hypertension, a raised jugular venous pressure, and atrial fibrillation, mitral stenosis may be suspected but will not always be found at operation.

\section{DEATHS}

Thirteen patients have died and the age at death is shown in Table X. Causes of death included pneumonia in 3 , infection with pulmonary artery thrombosis in 2 , congestive failure in 1 (during pregnancy), and operation in 6 . One patient died suddenly at home from an unknown cause, no necropsy being obtained. In the non-surgical deaths the duration of symptoms ranged from 1 to 19 years with an average of 8 years.

TABLE X

Deaths in A.S.D. with Pulmonary Hypertension

\begin{tabular}{|c|c|c|c|c|c|c|}
\hline & & & Total & $\begin{array}{c}\text { Average } \\
\text { age }\end{array}$ & $\begin{array}{l}\text { Range } \\
\text { of age }\end{array}$ & $\begin{array}{c}\text { Operative } \\
\text { deaths }\end{array}$ \\
\hline $\begin{array}{l}\text { Obstructive group } \\
\text { Hyperkinetic group } \\
\text { Lutembacher group }\end{array}$ & $\begin{array}{ll}. & \ldots \\
\cdots & \ldots \\
. & \end{array}$ & $\begin{array}{l}. . \\
\cdots\end{array}$ & $\begin{array}{l}8 \\
2 \\
3\end{array}$ & $\begin{array}{l}39 \\
47 \\
44\end{array}$ & $\begin{array}{r}9-63 \\
46-48 \\
41-46\end{array}$ & $\begin{array}{l}2 \\
2 \\
2\end{array}$ \\
\hline
\end{tabular}

The six surgical deaths included one patient operated on elsewhere with a pulmonary vascular resistance of 9 units, one with a common A-V canal, two with hyperkinetic hypertension, and two with Lutembacher's syndrome. The last four were all aged over 40, with vascular resistances of 2.5 to 4.5 units. Six patients with hyperkinetic hypertension, including one with Lutembacher's syndrome, had successful operations despite gross cardiac enlargement.

In the 12 necropsies, three had superior caval defects (one with mitral stenosis); two had a common A-V canal, including one, aged 44, with a large inferior caval defect; and 6 had central fossa-ovalis defects (2 with mitral stenosis). Pulmonary thrombosis was present in two patients dying during an acute respiratory infection and in three surgical deaths. Of the latter, one had a high vascular resistance of 9 units, one had a small aneurysm of the left pulmonary artery where thrombosis originated, and one had Lutembacher's syndrome.

\section{Operation in A.S.D. with PUlmonary Hypertension}

At the time of this investigation, 150 patients with A.S.D. had been operated on under hypothermia by Mr. Holmes Sellors and his colleagues at the Middlesex Hospital (Table XI), and these included 14 with pulmonary hypertension exceeding $50 \mathrm{~mm}$. $\mathrm{Hg}$ systolic. There were 8 with hyperkinetic hypertension with 2 deaths, and 6 with Lutembacher's syndrome with 2 deaths. In 
TABLE XI

150 Patients With A.S.D. Treated Surgically

\begin{tabular}{|c|c|c|c|c|}
\hline 137 patients without mitra & stenosis & & Number & Deaths \\
\hline With normal pressure & .. & . & 101 & 0 \\
\hline P.A.P. $30-49 \mathrm{~mm}$. & .. & . & 28 & 3 \\
\hline P.A.P. $50 \mathrm{~mm} .+$ & . & . & 8 & 2 \\
\hline \multicolumn{5}{|c|}{13 patients with Lutembacher's syndrome } \\
\hline With normal pressure & . & . & 2 & 0 \\
\hline P.A.P. $30-49 \mathrm{~mm}$. & . & .. & 5 & 0 \\
\hline P.A.P. $50 \mathrm{~mm} .+$ & . & . . & 6 & 2 \\
\hline
\end{tabular}

the 14 patients, the A.S.D. was large in 5, of moderate size in 6, and small in 3, two of which were superior caval defects. Those with obstructive hypertension were excluded from operation under hypothermia, and the only patient in this series operated on elsewhere, died at operation.

Re-catheterization a year or more after operation has been done in 4 hypertensive patients. In 3 hyperkinetic patients the average pulmonary systolic pressure fell from 66 to $20 \mathrm{~mm}$. $\mathrm{Hg}$, but the vascular resistance altered little, the average falling from $2 \cdot 7$ to $2 \cdot 1$ units. In the remaining patient with mitral stenosis, in whom a valvotomy was also performed, the P.A. pressure fell from 75 to $60 \mathrm{~mm} . \mathrm{Hg}$, whereas the vascular resistance rose from 3.5 to 5 units.

\section{The Ætiology of Pulmonary Hypertension in Atrial Septal Defect}

Dexter (1956) maintained that in secundum defects pulmonary hypertension is always acquired, and both Wood (1958) and Burchell (1958) found that it is less frequent and later in onset in A.S.D. than in ventricular septal defect and in patent ductus arteriosus. They believe, like Swan (1959), that pulmonary hypertension is acquired in A.S.D., but congenital in V.S.D., and P.D.A. Burchell suggested that, in congenital pulmonary hypertension, the heart is small compared with the large heart of acquired hypertension secondary to an increased pulmonary flow. Wood (1958) noticed that in the Eisenmenger syndrome gross cardiac enlargement was more than twice as common in those with A.S.D. as in those with ventricular or aorto-pulmonary shunts.

In order to investigate the question of a congenital or acquired origin of pulmonary hypertension in A.S.D., 13 cases of obstructive hypertension with relatively small hearts (c.t.r. less than 60 per cent) have been compared with 15 cases with relatively large hearts (c.t.r. exceeding 60 per cent) (see Table XII). Those with small hearts were on the average younger, had higher vascular resistances and smaller shunts than those with larger hearts. The younger average age in those with small hearts was due in part to the inclusion of 3 children aged 8-16 years, two being brother and sister. These differences, and the familial incidence, support the conception that, in some cases of A.S.D. pulmonary hypertension is congenital. Another possible explanation is that some of these cases actually have primary pulmonary hypertension, and that the A.S.D. is incidental or merely a widely patent foramen ovale. The average duration of symptoms before death in primary pulmonary hypertension is only $2 \frac{1}{2}$ years (Evans et al., 1957), whereas it is much longer in A.S.D. with pulmonary hypertension (10 years in this series) but this could be explained by the beneficial safety valve action of the A.S.D.

In the majority of cases of A.S.D., pulmonary hypertension is certainly acquired, and probably follows hyperkinetic hypertension. Burchell has reported one example in which the vascular resistance increased from 200 to 1700 dynes sec. $/ \mathrm{cm}^{-5}$ over 10 years, and Dexter has published 
TABLE XII

Comparison of Findings in Cases of Obstructive Hypertension with Cardio-Thoracic Ratios of Less than 60 PER CENT WITH THOSE IN CASES WITH LARGER HEARTS

\begin{tabular}{ll|c|c|c|c|c}
\hline & $\begin{array}{c}\text { No. of } \\
\text { cases }\end{array}$ & $\begin{array}{c}\text { Pulmonary/ } \\
\text { systemic } \\
\text { blood flows }\end{array}$ & $\begin{array}{c}\text { P.V.R. } \\
\text { (units) }\end{array}$ & $\begin{array}{c}\text { Cardio- } \\
\text { thoracic } \\
\text { ratio }\end{array}$ & Age \\
\hline Cardio-thoracic ratio $<60 \%$ &.. & 13 & $0.9 / 1 \cdot 0$ & 16 & $52 \%$ & $\begin{array}{c}30 \\
(8-58)\end{array}$ \\
\hline Cardio-thoracic ratio $>60 \%$ &.. & 15 & $1 \cdot 6 / 1 \cdot 0$ & 10 & $67 \%$ & $\begin{array}{c}43 \\
(30-67)\end{array}$ \\
\hline
\end{tabular}

similar observations. Hyperkinetic pulmonary hypertension may persist for many years without increasing the vascular resistance, as in two patients aged 70 reported by Kelly (1958), but in some the resistance increases and obstuctive hypertension develops. Sometimes this is due to pulmonary thrombosis, and Dexter (1959) suggests that a high output may eventually lead to right ventricular failure with reduced output and stagnant pulmonary thrombosis.

Respiratory infection plays an important part in the pulmonary hypertension of chronic lung disease, and the same may well apply to A.S.D., in which pulmonary thrombosis is often related to infection. In 13 patients with obstructive hypertension and a long history of recurrent bronchitis and pneumonia, the average cardio-thoracic ratio was 67 per cent, whereas in 13 with no such history of lung infection, the average ratio was 56 per cent. This suggests that in those with large hearts pulmonary hypertension is acquired and may be associated with lung infection, whereas in those with small hearts the hypertension is congenital and unrelated to infection.

Wood (1958) has suggested that, in cases of A.S.D. with normal pulmonary arterial pressures, the high resistance fotal pattern of pulmonary vasculature has evoluted completely to the low resistance adult type, whereas in those with hyperkinetic hypertension this evolution has been less complete. This would account for the slightly raised vascular resistance usually found in hyperkinetic hypertension. Similarly, congenital pulmonary hypertension in A.S.D. could be explained by a more complete persistence of the fœtal type of vasculature.

Thus in A.S.D. we may envisage the pulmonary vascular resistance behaving in four ways.

(1) It may remain normal despite a high flow.

(2) It may be slightly raised from birth, resulting in hyperkinetic hypertension which persists unchanged.

(3) In some cases of hyperkinetic hypertension, the resistance may increase with advancing age, and result in acquired obstructive hypertension. Respiratory infection and thrombosis may be factors in increasing the resistance.

(4) It may remain high from birth owing to a persistence of the fœtal pattern of pulmonary vasculature. In such cases, pulmonary hypertension is congenital, and at least 10 per cent of the obstructive group in this series are probably explained in this way.

\section{SUMMARY AND CONCLUSIONS}

Forty-one patients with atrial septal defect complicated by significant pulmonary hypertension have been investigated. The hypertension was classed as obstructive when the pulmonary vascular resistance exceeded 5 units ( 400 dynes sec. $/ \mathrm{cm}^{-5}$ ) or when there was central cyanosis with a reversed atrial shunt: it was classed as hyperkinetic when the resistance was below 5 units and the pulmonary flow much increased. Pulmonary hypertension complicating Lutembacher's syndrome, though usually hyperkinetic, has been separately considered.

The overall incidence of pulmonary hypertension in 225 patients with A.S.D. was 16 per cent, but it was far more frequent in superior caval defects, in primum defects with common A-V canal, 
and in Lutembacher's syndrome than in ordinary fossa-ovalis defects. Female predominance was twice as great in A.S.D. with pulmonary hypertension as in A.S.D. as a whole.

Anginal pain, effort syncope, central cyanosis, and pulmonary regurgitation were only encountered in obstructive hypertension which modified the usual clinical signs of A.S.D. in a characteristic way. In both types of pulmonary hypertension, the electrocardiogram usually showed inversion of the T waves in the chest leads from leads V1 to V5 or even V6. The pattern of QRS in V1 was not characteristic, but the R/S ratios in V1 and V6 were of some value in the diagnosis of pulmonary hypertension.

Surgical closure of the A.S.D. was performed in 14 patients with hyperkinetic pulmonary hypertension, including 6 with Lutembacher's syndrome, with 4 deaths. Patients with obstructive hypertension were excluded from operation under hypothermia.

The ætiology of pulmonary hypertension in A.S.D. has been discussed. In about 10 per cent of such patients, obstructive hypertension is probably congenital and due to a persistence of the fotal type of pulmonary vasculature: in these, the heart is relatively small. In the majority, obstructive pulmonary hypertension is probably acquired and follows hyperkinetic hypertension. Pulmonary thrombosis and recurrent respiratory infection are probably factors in provoking acquired pulmonary hypertension of the obstructive kind. The heart is much larger in the acquired than in the congenital form of pulmonary hypertension and the largest hearts occur in Lutembacher's syndrome.

I am most grateful for the invaluable help, advice, and encouragement given to me by Dr. D. Evan Bedford and Dr. W. Somerville in the preparation of this paper.

\section{REFERENCES}

Bedford, D. E. (1960). Amer. J. Card., 6, 568.

—, Papp, C., and Parkinson, J. (1941). Brit. Heart J., 3, 37.

, and Sellors, T. H. (1960). Modern Trends in Cardiology. Butterworth, London.

Burchell, H. B. (1958). St. Cyres Lecture. Brit. Heart J., 21, 255, 1959

Campbell, M., Neill, C., and Suzman, S. (1957). Brit. med. J., 1, 1375.

Dexter, L. (1956). Brit. Heart J., 18, 209.

- (1959). International Symposium on Pulmonary Circulation, 1958. Grune and Stratton, New York.

Evans, W., Short, D. S., and Bedford, D. E. (1957). Brit. Heart J., 19, 93.

Keith, J. D., Rowe, R. D., and Vlad, P. (1958). Heart Disease in Infancy and Childhood. Macmillian, New York.

Kelly, J. J., and Lyons, H. A. (1958). Ann. intern. Med., 48, 267.

Liddle, H. V., Meyer, B. W., and Jones, J. C. (1960). J. thor. card. Surgery, 39, 35.

McGoon, D. C., Swan, H. J. C., Brandenberg, R. O., Connolly, D. C., and Kirklin J. W. (1959). Circulation, 19, 195.

Scebat, L., Voridis, E., Renais, J., and Lenegre, J. (1957). Arch. Mal. Caeur., 50, 801.

Swan, H. J. C., Zapata-Diaz, J., Burchell, H. B., and Wood, E. H. (1954). Amer. J. Med., 16, 12.

, Kortz, A. B., Davies, D. H., and Blount, S. G. (1959). J. thor. Surg., 7, 52.

Wood, P. (1958). Brit. med. J., 2, 701 and 755. 